\title{
Endotoxin contamination in the dental surgery
}

\begin{abstract}
Correspondence
M. K. Huntington

mark.huntington@usd.edu
\end{abstract}

Received 14 February 2007

Accepted 24 May 2007

\author{
M. K. Huntington, ${ }^{1} \dagger$ J. F. Williams ${ }^{1} \ddagger$ and C. D. Mackenzie ${ }^{2}$ \\ ${ }^{1}$ Department of Microbiology, B514 West Fee Hall, Michigan State University, East Lansing, \\ MI 48824, USA \\ ${ }^{2}$ Department of Pathology, B514 West Fee Hall, Michigan State University, East Lansing, \\ MI 48824, USA
}

\begin{abstract}
Dental waterlines contain large numbers of Gram-negative bacteria. Endotoxin, a component of such organisms, has significant health implications. Paired samples of dental unit water and the aerosols generated during dental procedures were collected, and assayed for bacteria and endotoxin levels, using heterotrophic plate counts and the Limulus amoebocyte lysate test. Consistent with published studies, the extent of bacterial contamination in the dental waters sampled for this investigation surpassed the levels associated with potable water, with counts in excess of $2.0 \times 10^{6}$ c.f.u. $\mathrm{ml}^{-1}$ in some samples. Correspondingly high concentrations of endotoxin [up to 15000 endotoxin units (EU) $\mathrm{ml}^{-1}$ ] were present in the water. A statistically significant Spearman correlation coefficient of $\rho=0.94$ between endotoxin $\left(E U \mathrm{ml}^{-1}\right)$ and bacterial load (c.f.u. $\mathrm{ml}^{-1}$ ) was demonstrated. All of the aerosol samples contained detectable endotoxin. Further studies of the consequences of dental endotoxin exposure, and evaluation of means to prevent exposure, are warranted.
\end{abstract}

\section{INTRODUCTION}

Endotoxin, a heat-stable toxin associated with Gramnegative bacterial cells, is composed of LPS derived from the bacterial cell wall. Most of the pathogenic effects seen in Gram-negative bacterial infections are mediated by an endotoxin (Natanson et al., 1994); the associated clinical syndrome may even occur in the absence of bacteraemia (Danner et al., 1991; Graham \& Brass, 1994). Endotoxin has been implicated in the pathogenesis of hepatotoxicity, hepatorenal failure, hepatic encephalopathy (Shibayama, 1992; Odeh, 1994), periodontitis (Trope et al., 1995), mastitis (Tyler et al., 1994), adult respiratory distress syndrome (Herbert et al., 1992; Graham \& Brass, 1994), disseminated intravascular coagulation (Graham \& Brass, 1994), humidifier fever (Flaherty et al., 1984; Mamolen et al., 1993) and sick building syndrome (Teeuw et al., 1994).

Dental unit waterlines are lined by a thriving biofilm composed predominantly of Gram-negative heterotrophic bacteria (Mayo et al., 1990; Pankhurst \& Philpott-Howard, 1993; Williams et al., 1993). These organisms are released in high numbers into the dental unit coolant and irrigant water(s), and delivered through the distal outlet of the

tPresent address: Center for Family Medicine, 1115 East Twentieth Street, Sioux Falls, SD 57105, USA.

łPresent address: Vanson HaloSource, Inc., 14716 NE 87th Street, Redmond, WA 98052, USA.

Abbreviations: CDC, Centers for Disease Control and Protection; EU, endotoxin unit; LAL, Limulus amoebocyte lysate. dental instrument. With them is delivered the potential for endotoxin exposure.

In pharmaceutical products, endotoxin concentrations in fluids have to be carefully controlled and United States Pharmacopoeia (USP) standards for irrigation and parenteral fluids must be observed (USDHHS, 1987). The Centers for Disease Control and Protection (CDC) currently recommends that USP sterile water be used for all dental surgical procedures, and this stipulation requires the use of 'pyrogen-free' irrigant (USDHHS, 1987; CDC, 1993).

Despite the fact that there are numerous reports of Gramnegative bacteria in dental water, there is a paucity of published reports investigating dental water endotoxin (Bourassa et al., 1995; Putnins et al., 2001; Fulford et al., 2004; Szymanska, 2005a, b).

Three questions were asked in the present study. (i) Are there significant levels of endotoxin in dental water? (ii) Is there any correlation between the number of bacteria and the level of endotoxin present in dental water? (iii) Is endotoxin aerosolized in detectable levels by routine dental procedures?

\section{METHODS}

Water and aerosol samples. Water samples were collected from the dental lines of operatories, as dental surgeries are called in the USA, in a large institutional setting and processed according to standard practices for water-quality evaluation using heterotrophic bacterial 
plate counts (APHA, 1985). Samples $(2-3 \mathrm{ml})$ were collected in sterile, pyrogen-free $12 \times 75$ polystyrene tubes, avoiding any contact between the instrument parts and the tube during collection. Samples were shipped overnight to the laboratory at $4^{\circ} \mathrm{C}$.

Aerosols were collected using AGI-30 glass impingers (Ace Glass) containing endotoxin-free sterile water, as described by Trudeau \& Fernandez-Caldas (1994). Impingers were set up at a distance of $60 \mathrm{~cm}$ from the area of dental work in a patient's mouth and a total of $0.33 \mathrm{~m}^{3}$ of air was sampled for each of eight tested operatories: four from operatories using ultrasonic scaler lines and four from operatories using high-speed handpiece lines. Control collections were done in the early morning prior to the generation of any dental aerosols. Samples were shipped on ice via overnight courier and analyzed for endotoxin.

In view of the natural day-to-day fluctuations in bacterial contamination in dental water (Santiago et al., 1994), both water and aerosol samples were obtained on multiple occasions, ultimately providing 47 separate water/aerosol pairs for our analyses.

Bacterial contamination. Bacterial contamination of the water samples was assessed by plating $100 \mu$ l aliquots of serial dilutions of each sample onto R2A plates and incubating as described previously (Williams et al., 1993).

At each of the aerosol collection sites, additional collections were made using Anderson plate chambers. In this procedure, air is drawn over the surface of agar plates through steel plates, which deflect the particles onto the surface of the R2A agar for subsequent incubation and colony formation (Turner \& Hill, 1975). In this way, the number of bacteria may be determined qualitatively, and the resultant colonies permit standard microbiological isolation and identification methods to be applied.

Endotoxin assay. The presence of endotoxin in the samples was assessed using the Limulus amoebocyte lysate (LAL) test (USDHHS, 1987), commercially available as a Pyrotell kit (Associates of Cape

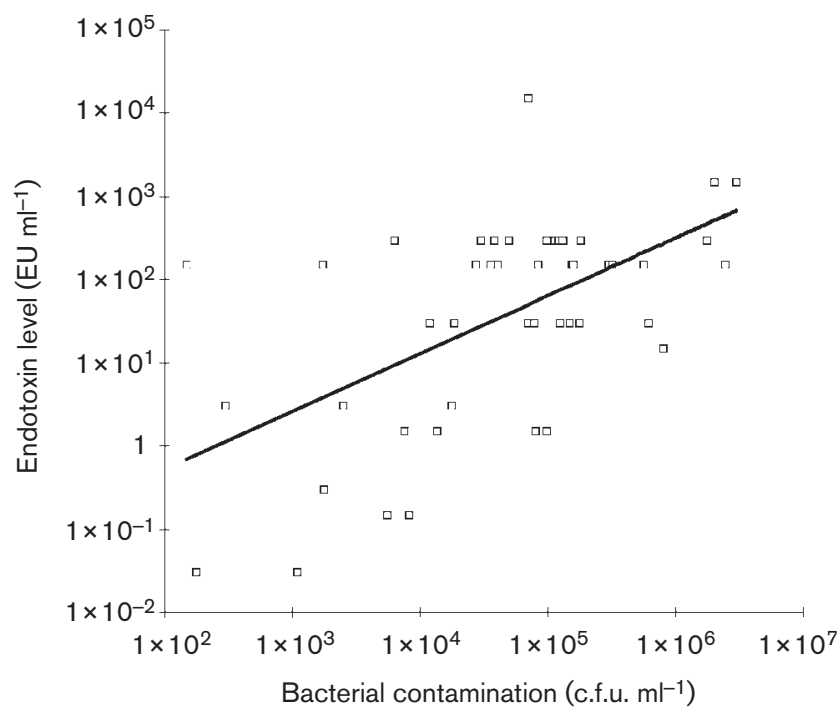

Fig. 1. Correlation between bacterial contamination and endotoxin levels in dental waterline samples. A positive correlation with a Spearman's rank correlation coefficient of $\rho=0.94$ between bacterial load and endotoxin level, significant at $P<0.05$, is evident. Note both axes are logarithmic.
Cod). The LAL assay is exquisitely sensitive to endotoxin, and mandates devoted adherence to the use of endotoxin-free glassware and plasticware (including tubes and pipette tips), diluent, etc. The assay was performed in accordance with the specified protocol. Results were obtained in endotoxin units (EU); $10 \mathrm{EU}$ corresponds to $1 \mathrm{ng}$ endotoxin. Commercially available endotoxin standards were used as controls.

Statistical analysis. The Spearman rank correlation coefficient for non-parametric data was employed to analyse the relationship between endotoxin and bacterial contamination levels.

\section{RESULTS AND DISCUSSION}

\section{Contamination levels}

Consistent with all studies to date, the extent of bacterial contamination in the dental waters sampled for this investigation far surpassed the levels associated with potable water, with counts in excess of $2.0 \times 10^{6}$ c.f.u. $\mathrm{ml}^{-1}$ in some samples. Correspondingly high concentrations of endotoxin (up to $15000 \mathrm{EU} \mathrm{ml}^{-1}$ ) were present.

The relationship between bacterial concentrations and the results of the endotoxin assay are shown in Fig. 1. A Spearman rank correlation coefficient of $\rho=0.94$ between $\mathrm{EU} \mathrm{ml} \mathrm{m}^{-1}$ and c.f.u. $\mathrm{ml}^{-1}$ was demonstrated, which was significant at $P<0.05$.

Aerosol sample cultures produced a varied mixture of bacterial organisms, which were rapidly overgrown by the abundant growth of a number of fungal varieties. This precluded quantification of bacterial numbers in aerosols. Nevertheless, a variety of bacteria was isolated, including Gram-positive cocci, Gram-positive coccobacilli, Gramnegative cocci and Gram-negative bacilli. Not all of the isolates were identifiable using standard microbiological and biochemical profiling techniques, but of those that could be definitively assigned to species, the following were found: Staphylococcus epidermidis, Staphylococcus aureus, Staphylococcus haemolytica, Micrococcus spp., Micrococcus varians roseus, Pseudomonas vesicularis, Sphingomonas paucimobilis, Acinetobacter spp. and Flavomonas spp.

All of the aerosol samples collected in impingers contained detectable endotoxin, although the concentration did not exceed $2.7 \mathrm{EU} \mathrm{m}^{-3}$ in any instance. No endotoxin was detectable in control air samples.

Water obtained from properly functioning distillation, reverse osmosis and ultrafiltration systems generally has undetectable levels of endotoxin. Clearly, the concentrations seen in the dental water samples far exceeded any acceptable standard for water intended for medical purposes. The generally acknowledged range of 0.06$0.5 \mathrm{EU} \mathrm{ml}^{-1}$ for medical devices (including liquid devices), depending on application, applies to irrigation fluids and is regulated by the US federal government (USDHHS, 1993).

We found levels of endotoxin in dental water several orders of magnitude below that reported in two published reports, 
both from the same investigator (Szymanska 2005a, b). Compared with others (Putnins et al., 2001; Fulford et al., 2004), our water endotoxin levels exhibited a broader range of values, encompassing their results but extending to both higher and lower levels. The reason for the discrepancy with the former (Szymanska 2005a, b) is not clear. Such a large difference in endotoxin level cannot be attributable solely to microbial content of the waterlines, as c.f.u. counts between those studies and ours were comparable. It is possible that significantly higher levels of endotoxin existed in the municipal water supplying the operatory and were showing up in the efflux. This would also explain the lack of correlation between dental water microbial levels and endotoxin found in the study. It is also conceivable that an unfortunate typographical error (mislabelling EU values as $\mu$ g, a difference of several orders of magnitude) could have occurred, although this is deemed less likely as it would require the same error to persist through the peer-review process for two papers. Still, this is tempting to consider, as reading the endotoxin levels as EU rather than $\mu \mathrm{g}$ would bring these values into close agreement with that seen in this study, and those of Fulford et al. (2004) and Putnins et al. (2001). Aerosolized endotoxin levels documented in the present study were also exponentially lower than those found by Szymanska (2005a), who also found that disinfection of the dental unit waterlines, whilst decreasing the level of endotoxin detectable in the water, had no significant effect on the aerosolized endotoxin levels.

In light of the significant correlation demonstrated in Fig. 1, the proximate source of the dental water endotoxin contamination is likely to be the Gram-negative organisms resident in the dental waterline biofilms (Mayo et al., 1990; Pankhurst \& Philpott-Howard, 1993; Williams et al., 1993). The correlation between bacterial and endotoxin contamination levels observed in this study is at odds with the findings of others (Bourassa et al., 1995; Fulford et al., 2004; Szymanska, 2005b). In those studies, a correlation between the levels was sought as a 'simple test for monitoring bacterial contamination'. They found no significant relationship between c.f.u. and endotoxin concentrations, even when the c.f.u. varied by up to three orders of magnitude. One group (Bourassa et al., 1995) proposed that this lack of relationship may be due to bacterially produced inhibitors of the Limulus chromogenic test employed in their investigation (Roth et al., 1990). The LAL assay may, in fact, be less prone than the chromogenic test to such inhibitors. However, another investigator failed to demonstrate a significant correlation using the same LAL techniques employed in our laboratory (Szymanska, 2005b), although the possibility of exogenous endotoxin being supplied in the municipal water could confound this, as noted above. The range of both bacterial and endotoxin levels found in our study was broader than that seen by Fulford et al. (2004), and could explain why a statistically significant correlation was not found in the latter. Other explanations could relate to sample size, variation in aliquot-handling technique or contamination of diluents or laboratory-ware by exogenous endotoxins. Whatever the cause of the differences, whilst there is not an adequate basis on which to compute the number of bacteria $\mathrm{ml}^{-1}$, the correlation between endotoxin and c.f.u. $\mathrm{ml}^{-1}$ is clear.

\section{Implications}

The presence of endotoxin in dental water has potential clinical significance, both medically and dentally. Endotoxin stimulates the production of numerous cytokines, which resulting in tissue injury (Graham \& Brass, 1994). These may inhibit healing following dental or periodontal treatment. The significance of endotoxin in the pathogenesis of periodontitis is well documented (Trope et al., 1995), and irrigation of highly vascular mucosal lesions with endotoxin-laden water during treatment for this condition is, at the very least, medically inappropriate. Irrigation of the site of any dental intervention with endotoxin-laden water has the potential for introduction of the endotoxin into the patient's bloodstream. Experimental injection of endotoxin into the systemic circulation of healthy volunteers elicits the signs and symptoms of endotoxaemia, including fever, elevated white blood cell count, elevated blood concentrations of stress hormones and decreased blood oxygenation (Suffredini et al., 1989; van Deventer et al., 1990; Herbert et al., 1992). Endotoxaemia is typically associated with infection, but significant exposure via inhalation (Castellan et al., 1987; Teeuw et al., 1994) has been reported. Little is known about the significance of aspiration, ingestion, mucosal or dermal exposure.

Of potentially greater significance than the occasional endotoxin exposure of patients undergoing dental care is the continuous exposure of those involved in the dental and dental-hygiene professions. Chronic endotoxin inhalation represents an occupational hazard to these groups. In other settings, Gram-negative organisms in the biofilms of plumbing and climate-control ductwork contribute medically significant quantities of endotoxin to their surroundings (Costerton et al., 1987; Hugenholtz \& Fuerst, 1992; Szymanska, 2005b). Inhaled endotoxin significantly lowers spirometric values in otherwise healthy subjects (Castellan $e t$ al., 1987; Herbert et al., 1992). Breathing endotoxin-tainted air has serious implications for exacerbation of chronic obstructive pulmonary disease and asthma in individuals with pre-existing conditions (Michel et al., 1996). Studies linking airborne endotoxin to sick building syndrome (Teeuw et al., 1994) suggest that even uncompromised individuals are at risk for the development of medical conditions due to inhaled endotoxin. Inhaled endotoxin has been suggested as the source of occupationally acquired asthma in dentists (Pankhurst et al., 2005). Whilst there is no specific concentration of airborne endotoxin above which is defined as hazardous, experimental animals show respiratory dysfunction at $0.3 \mu \mathrm{g} \mathrm{m}^{-3}$. The use of face masks to prevent exposure is marginal at best, with inconsistent 
effects that are heavily dependent on aerosol droplet size and a host of other variables (Lipp, 2003).

In addition to the clinical implications of dental water endotoxin, there are medico-legal ramifications. On top of the potential liability incurred by exposing patients to endotoxin, there is risk from an employee health perspective. In the USA, the Indoor Clean Air Act Amendments of 1990 mandate that, within buildings, exposure to airborne pollutants cannot exceed levels of exposure in the local outside air: dental office airborne endotoxin exposure may cross that threshold. The European Commission similarly regulates indoor air quality in the workplace (Stevens \& Palmigianob, 1995). A World Health Organization working group has issued statements delineating the right to healthy indoor air, statements that have been successfully cited in lawsuits (Molhave \& Krzyzanowski, 2003). Blaming an exacerbation of chronic obstructive pulmonary disease or asthma on workplace exposures could lead to both civil and criminal penalties.

The endotoxin literature contains an interesting report on the inhibition of Legionella growth within endotoxin-treated macrophages (Egawa et al., 1992). In this study, macrophages from a murine strain permissive for Legionella growth became highly resistant to growth of the organism when pre-treated with endotoxin. This enhanced cytolytic activity occurs at some point subsequent to the initial bacteria-macrophage interaction. It is tempting to speculate that the high levels of endotoxin delivered in dental water might exert some sort of protective effect, contributing to the infrequency of severe legionellosis in those exposed (Fotos et al., 1985; Reinthaler et al., 1988) to the high levels of Legionella present in dental water (Atlas et al., 1995).

Efforts to control the dental-line biofilm, the source of endotoxin in the dental operatory, have been largely disappointing. Flushing, long advocated as a solution, has been shown to be of no benefit (Santiago et al., 1994), and biofilms are resistant to chemical disinfection (Mills \& Karpay, 2002). Filtration is effective at removing the planktonic bacteria from the dental water (Mayo \& Brown, 1999), but has no effect on the core biofilm and its endotoxin production.

In conclusion, this study has demonstrated that dental unit water contains high concentrations of endotoxin, and that there is a statistically significant positive correlation between endotoxin and the bacterial load present. This water is readily aerosolized during routine dental work. Exposure to either the endotoxin-laden water or the aerosolized endotoxin represents a potential health threat. Further epidemiological and clinical studies of the consequences of dental endotoxin exposure, and the means by which this exposure may be prevented, are warranted.

\section{ACKNOWLEDGEMENTS}

The authors wish to thank Debra Hunter-Simon for her technical assistance.

\section{REFERENCES}

APHA (1985). Standard Methods for the Examination of Water and Wastewater, 16th edn. Washington, DC: American Public Health Association.

Atlas, R. M., Williams, J. F. \& Huntington, M. K. (1995). Legionella contamination of dental-unit waters. Appl Environ Microbiol 61, 1208-1213.

Bourassa, N., Grenier, D., Mayrand, D., Morin, J. \& Dufour, L. (1995). Bacterial analysis of dental unit waterlines. J Dent Res 74, 153.

Castellan, R. M., Olenchock, S. A., Kinsley, K. B. \& Hankinson, J. L. (1987). Inhaled endotoxin and decreased spirometric values. An exposure-response relation for cotton dust. N Engl J Med 317, 605-610.

CDC (1993). Recommended infection control practices for dentistry. MMWR Morb Mortal Wkly Rep 42, 1-12.

Costerton, J. W., Cheng, K. J., Geesey, G. G., Ladd, T. I., Nickel, J. C., Dasgupta, M. \& Marrie, T. J. (1987). Bacterial biofilms in nature and disease. Annu Rev Microbiol 41, 435-464.

Danner, R. L., Elin, R. J. \& Hosseini, J. M. (1991). Endotoxemia in human septic shock. Chest 99, 169-175.

Egawa, K., Klein, T. W., Yamamoto, Y., Newton, C. A. \& Friedman, H. (1992). Enhanced growth restriction of Legionella pneumophila in endotoxin-treated macrophages. Proc Soc Exp Biol Med 200, 338-342.

Flaherty, D. K., Deck, F. H., Cooper, J., Bishop, K., Winzenburger, P. A., Smith, L. R., Bynum, L. \& Witmer, W. B. (1984). Bacterial endotoxin isolated from a water spray humidification system as a putative agent of occupation-related lung disease. Infect Immun 43, 206-212.

Fotos, P. G., Westfall, H. N., Snyder, I. S., Miller, R. W. \& Mutchler, B. M. (1985). Prevalence of Legionella-specific IgG and IgM antibody in a dental clinic population. J Dent Res 64, 1382-1385.

Fulford, M. R., Walker, J. T., Martin, M. V. \& Marsh, P. D. (2004). Total viable counts, ATP, and endotoxin levels as potential markers of microbial contamination of dental unit water systems. Br Dent J 196, 157-159.

Graham, P. \& Brass, N. J. (1994). Multiple organ dysfunction: pathophysiology and therapeutic modalities. Crit Care Nurs Q 16, 8-15.

Herbert, A., Carvalheiro, M., Rubenowitz, E., Bake, B. \& Rylander, R. (1992). Reduction of alveolar-capillary diffusion after inhalation of endotoxin in normal subjects. Chest 102, 1095-1098.

Hugenholtz, P. \& Fuerst, J. A. (1992). Heterotrophic bacteria in an air-handling system. Appl Environ Microbiol 58, 3914-3920.

Lipp, A. (2003). The effectiveness of surgical face masks: what the literature shows. Nurs Times 99, 22-24.

Mamolen, M., Lewis, D. M., Blanchet, M. A., Satink, F. J. \& Vogt, R. L. (1993). Investigation of a outbreak of "humidifier fever" in a print shop. Am J Ind Med 23, 483-490.

Mayo, J. A. \& Brown, C. E. (1999). Effect of in-line bacteriological filters on numbers of heterotrophic bacteria in water emitted from non-autoclavable dental air-water syringes. Am J Dent 12, 256-260.

Mayo, J. A., Oertling, K. M. \& Andrieu, S. (1990). Bacterial biofilm: a source of contamination in dental air-water syringes. Clin Prev Dent $12,13-20$.

Michel, O., Kips, J., Duchateau, J., Vertongen, F., Robert, L., Collet, H., Pauwels, R. \& Sergysels, R. (1996). Severity of asthma is related to endotoxin in house dust. Am J Respir Crit Care Med 154, 1641-1646.

Mills, S. E. \& Karpay, R. I. (2002). Dental waterlines and biofilm searching for solutions. Compend Contin EducDent 23, 237-240, 242, 244. 
Molhave, L. \& Krzyzanowski, M. (2003). The right to healthy indoor air: status by 2002. Indoor Air 13, 50-53.

Natanson, C., Hoffman, W. D., Suffredini, A. F., Eichacker, P. Q. \& Danner, R. L. (1994). Selected treatment strategies for septic shock based on proposed mechanisms of pathogenesis. Ann Intern Med 120, 771-783.

Odeh, M. (1994). Endotoxin and tumor necrosis factor- $\alpha$ in the pathogenesis of hepatic encephalopathy. J Clin Gastroenterol 19, 146-153.

Pankhurst, C. L. \& Philpott-Howard, J. N. (1993). The microbiological quality of water in dental chair units. J Hosp Infect 23, 167-174.

Pankhurst, C. L., Coulter, W., Philpott-Howard, J. N., Surman-Lee, S., Warburton, F. \& Challacombe, S. (2005). Evaluation of the potential risk of occupational asthma in dentists exposed to contaminated dental unit waterlines. Prim Dent Care 12, 53-59.

Putnins, E. E., DiGiovanni, D. \& Bhullar, A. S. (2001). Dental unit waterline contamination and its possible implications during periodontal surgery. J Periodontol 72, 393-400.

Reinthaler, F. F., Mascher, F. \& Stunzner, D. (1988). Serological examination for antibodies against Legionella species in dental personnel. J Dent Res 67, 942-943.

Roth, R. I., Levin, F. C. \& Levin, J. (1990). Optimization of detection of bacterial endotoxin in plasma with the Limulus test. J Lab Clin Med 116, 153-161.

Santiago, J. I., Johnston, A. M., Williams, J. F. \& Huntington, M. K. (1994). Microbial contamination of dental unit waterlines: short- and long-term effects of flushing. J Acad Gen Dent 42, 528-535.

Shibayama, Y. (1992). Role of lipid peroxidation in enhancement of endotoxin hepatotoxicity. Exp Toxicol Pathol 44, 205-208.

Stevens, R. \& Palmigianob, P. (1995). The European Union: its compliance and activities within the fields of outdoor and indoor air quality. Indoor Built Environ 4, 344-354.

Suffredini, A. F., Fromm, R. E. \& Parker, M. M. (1989). The cardiovascular response of normal humans to the administration of endotoxin. N Engl J Med 321, 280-287.
Szymanska, J. (2005a). Exposure to bacterial endotoxin during conservative dental treatment. Ann Agric Environ Med 12, 137-139.

Szymanska, J. (2005b). Endotoxin levels as a potential marker of concentration of Gram-negative bacteria in water effluent from dental units and in dental aerosols. Ann Agric Environ Med 12, 229-232.

Teeuw, K. B., Vandenbroucke-Grauls, C. M. \& Verhoef, J. (1994). Airborne Gram-negative bacteria and endotoxin in sick building syndrome. Arch Intern Med 154, 2339-2345.

Trope, M., Chow, E. \& Nissan, R. (1995). In vitro endotoxin penetration of coronally unsealed endodontically treated teeth. Endod Dent Traumatol 11, 90-94.

Trudeau, W. L. \& Fernandez-Caldas, E. (1994). Identifying and measuring indoor biologic agents. J Allergy Clin Immunol 94, 393400.

Turner, A. G. \& Hill, N. F. (1975). Calibration of the Anderson 2000 disposable air sampler. Am Ind Hyg Assoc J 36, 447-451.

Tyler, J. W., Welles, E. G., Erskine, R. J., Lin, H. C., Williams, M. A., Spano, J. S., Gaslin, J. T. \& McClure, K. A. (1994). Clinical and clinicopathologic changes in cows with endotoxin-induced mastitis treated with small volumes of isotonic or hypertonic sodium chloride administered intravenously. Am J Vet Res 55, 278-287.

USDHHS (1987). Guidelines on validation of the Limulus amebocyte lysate test as an end-product endotoxin test for human and animal parenteral drugs, biological products, and medical devices. Washington, DC: US Department of Health and Human Services, Food and Drug Administration.

van Deventer, S. J. H., Buller, H. R., TenCate, J. W., Aarden, L. A., Hack, C. E. \& Sturk, A. (1990). Experimental endotoxemia in humans: analysis of cytokine release and coagulation, fibrinolytic, and complement pathways. Blood 76, 2520-2526.

Williams, J. F., Johnston, A. M., Johnson, B., Huntington, M. K. \& Mackenzie, C. D. (1993). Microbial contamination of dental unit water lines: prevalence, intensity and microbiological characteristics. $J$ Am Dent Assoc 124, 59-65. 